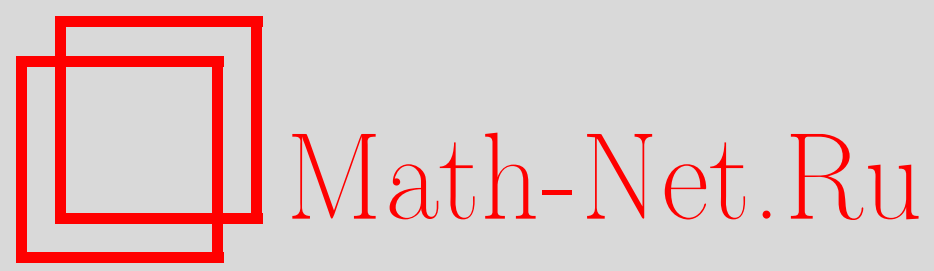

О. А. Кашин, Е. Ф. Дударев, Ю. Р. Колобов, Н. В. Гирсова, Н. Б. Иванов, Р. 3. Валиев, Деформационное поведение и разрушение субмикрокристаллического титана при циклическом нагружении, Вестн. Сам. гос. техн. ун-та. Сер. Физ.-мат. науки, 2004, выпуск 27, 130-134

DOI: https://doi.org/10.14498/vsgtu289

Использование Общероссийского математического портала Math-Net.Ru подразумевает, что вы прочитали и согласны с пользовательским соглашением http://www.mathnet.ru/rus/agreement

Параметры загрузки:

IP : 52.6 .47 .48

26 апреля 2023 г., $11: 15: 37$ 


\title{
ДЕФОРМАЦИОННОЕ ПОВЕДЕНИЕ И РАЗРУШЕНИЕ СУБМИКРОКРИСТАЛЛИЧЕСКОГО ТИТАНА ПРИ ЦИКЛИЧЕСКОМ НАГРУЖЕНИИ
}

\begin{abstract}
Исследованы закономерности развития деформационных процессов при усталостном нагружении субмикрокристаллического титана технической чистоты ВТ1-0, полученного методом равноканального углового прессования. Показано, что создание субмикрокристаллической структуры приводит к замедлению скорости накопления остаточной деформации при ииклическом нагружении, повышению долговечности и предела выносливости. На основании анализа закономерностей накопления остаточной деформачии, характера зарождения и распространения магистральной трещины, эволюции микроструктуры сделано предположение о возможном механизме усталостного разрушения СМК титана.
\end{abstract}

Титан технической чистоты является наиболее предпочтительным материалом для длительно работающих в живом организме имплантатов вследствие его высокой биосовместимости и отсутствия вредных легирующих добавок. Однако в обычном состоянии он имеет низкие по сравнению с титановыми сплавами механические характеристики [1]. Эффект многократного увеличения прочности титана достигается путем формирования субмикрокристаллического (СМК) состояния воздействием интенсивной пластической деформации [2]. Метод равноканального углового (РКУ) прессования позволяет формировать субмикрокристаллическое состояние в объемных заготовках, имеющих размеры, достаточные для изготовления широкой номенклатуры изделий медицинского назначения.

В настоящей работе исследования выполнены на титане технической чистоты трех марок, отличающихся содержанием примесей. Составы исследованных материалов приведены в таблице.

Содержание примесей в исследованных материалах, вес. \%

\begin{tabular}{|c|c|c|c|c|c|}
\hline Марка & $\mathrm{O}$ & $\mathrm{N}$ & $\mathrm{C}$ & $\mathrm{Fe}$ & $\mathrm{H}$ \\
\hline BT1-0 & 0,12 & 0.04 & 0.07 & 0.18 & 0.01 \\
\hline Grade 2 & 0,14 & 0.006 & 0.009 & 0.08 & 0.009 \\
\hline Grade 4 & 0,34 & 0.006 & 0.006 & 0.35 & 0.019 \\
\hline
\end{tabular}

СМК состояние получали методом РКУ прессования. Электронно-микроскопические исследования показали, что средний размер элементов зеренно-субзеренной структуры после

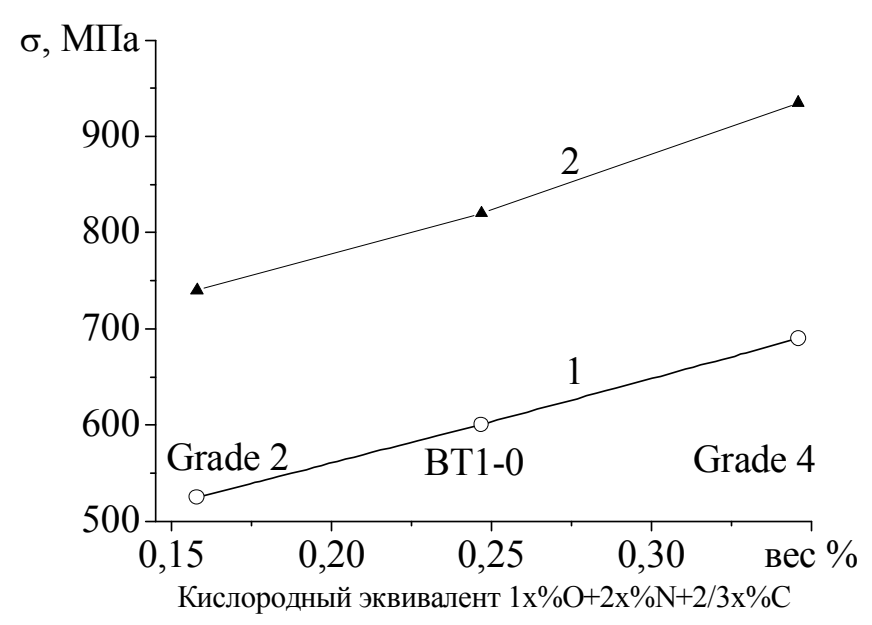

Р и с. 1. Зависимость предела прочности при комнатной температуре от кислородного эквивалента для исследованных сплавов в исходном состоянии (кривая 1) и после РКУ прессования (2)
РКУ прессования для всех исследованных материалов примерно одинаков и составляет $(0,35 \pm 0,15)$ мкм. На рис. 1 приведен график зависимости предела прочности от кислородного эквивалента. Видно, что предел прочности линейно возрастает с увеличением концентрации примесей как для исходного состояния, что совпадает с литературными данными [3], так и для состояния после РКУ прессования.

Усталостные испытания проводили на плоских образцах размером $45 \times 0,6 \times(0,2 \div 0,4)$ мм знакопостоянным изгибом по оправке заданного радиуса методом нагрузки-разгрузки [4]. В процессе испытаний определяли величину остаточной деформации после различного числа циклов. По характеру дан- 
ной зависимости можно судить об изменении механизмов деформации при соответствующем числе циклов.

Для выбора максимальных напряжений циклирования были определены зависимости накопления остаточной микропластической деформации при квазистатическом изгибе от уровня приложенных напряжений (рис. 2). Для удобства анализа график на рис. 2 приведен в виде $\sigma=f(\varepsilon)$. Для всех исследованных материалов на зависимостях накопления остаточной деформации от уровня приложенных напряжений можно выделить две стадии - линейную и параболическую. Согласно [5], линейная стадия соответствует пластической деформации отдельных, не контактирующих между собой зерен, а соседние зерна осуществляют упругую аккомодацию. Начало параболической стадии связано с кооперативной пластической деформацией зерен. На параболической стадии скорость накопления остаточной деформации с увеличением напряжения резко возрастает. В [5] на ряде материалов показано, что напряжение перехода от первой ко второй стадии (макроскопический предел упругости $\left.\sigma^{\prime \prime}\right)$ примерно соответствует пределу выносли-

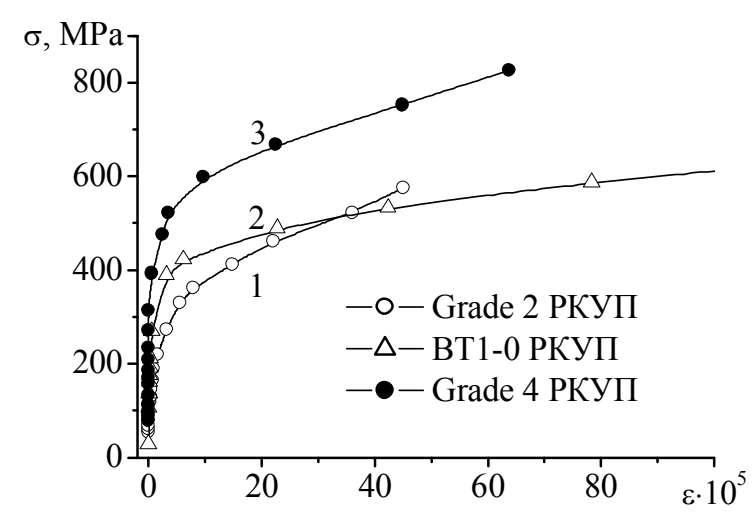

Р и с. 2. Зависимость накопления остаточной деформации от приложенного напряжения для исследованных материалов в состоянии после РКУ прессования вости или, по крайней мере, может характеризовать нижнюю границу значений предела выносливости. Из рис. 2 можно заключить, что для исследованных материалов напряжение перехода от первой ко второй стадии растет с увеличением концентрации примесей. Можно было ожидать, что и усталостная прочность будет выше для сплава Grade 4. Для определения ограниченного предела выносливости на базе $10^{6}$ циклов усталостные испытания начинали при максимальных напряжениях цикла $\sigma_{\max }$, соответствующих параболической стадии, а затем $\sigma_{\max }$ ступенчато уменьшали. Исследования показали, что ограниченный предел выносливости оказался практически одинаковым для всех исследованных материалов и равным 520 МПа, что выше такового для крупнозернистого материала примерно в 1,5 раза.

На рис. 3 приведены зависимости накопления остаточной деформации от числа циклов для исследованных материалов. За исключением образца Grade 4, испытанного при максимальном напряжении цикла $\sigma_{\max }=510$ МПа и выдержавшего без разрушения $10^{6}$ циклов, все остальные кривые приведены для образцов, разрушившихся при циклировании. Полученные зависимости для всех исследованных сплавов имеют одинаковый характер. На кривых накопления остаточной деформации можно выделить, по крайней мере, две стадии с различной скоростью накопления остаточной деформации. Визуальное наблюдение за поверхностью образца в процессе циклирования позволяет сказать, что последняя стадия - с максимальной скоростью накопления остаточной деформации - связана с образованием и быст-

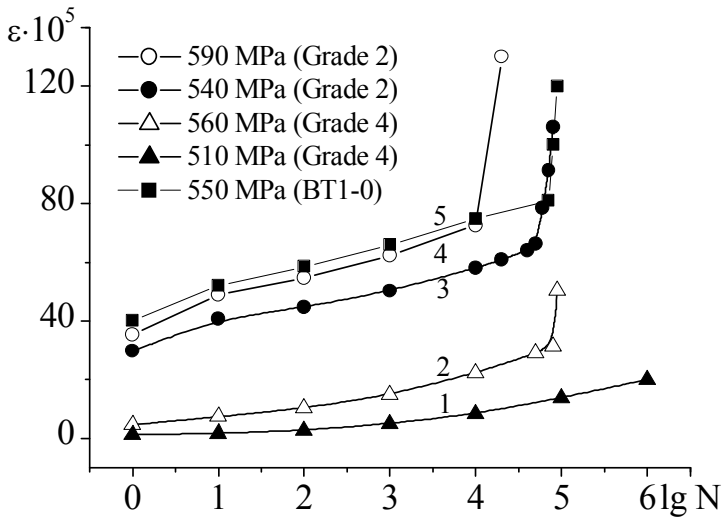

Р и с. 3. Зависимость накопления остаточной деформации от числа циклов для Grade 4 (кривые 1 и 2), Grade 2 (кривые 3 и 4), VT1-0 (кривая 5) в состоянии после РКУ прессования при различных значениях максимального напряжения цикла рым распространением магистральной трещины для всех исследованных материалов (рис. 3, кривые 2-5). На начальных стадиях накопление остаточной деформации с ростом числа циклов при сравнимых напряжениях циклирования идет медленнее для образцов Grade 4. Образцы Grade 2 и BT1-0 показали близкие значения. Из рисунка видно, что в исследованных материалах момент образования магистральной трещины и разрушение образца не зависит от абсолютной величины накопленной деформации (ср. кривые 2 и 5 на рис. 3). Таким образом, и при циклическом нагружении большей размерной стабильностью обладает титан технической чистоты с максимальной концентрацией примесей. 
Из-за особенностей использованной методики усталостных испытаний трудно однозначно судить об упрочнении или разупрочнении материала при увеличении числа циклов. Тем не менее, по зависимостям, приведенным на рис. 3, можно ориентировочно предположить, что вплоть до образования магистральной трещины заметного разупрочнения не происходит.

Для всех исследованных материалов при использованной схеме испытаний магистральная трещина зарождается на узкой боковой грани плоских образцов и распространяется до другой грани по схеме нормального отрыва за сравнительно небольшое количество циклов. Траектория трещины расположена практически нормально к продольной оси образца, хотя на ней имеется значительное количество изломов (рис. 4). Иногда наблюдается ветвление трещины, что в большей степени характерно для сплава Grade 4 с максимальной концентрацией примесей (рис. $4, a$ ). Следы пластической деформации хорошо видны в вершине трещин, особенно со стороны, подвергавшейся в процессе циклирования сжатию (рис. 4, б).

Характер излома практически одинаков для всех исследованных материалов (рис.5). По-
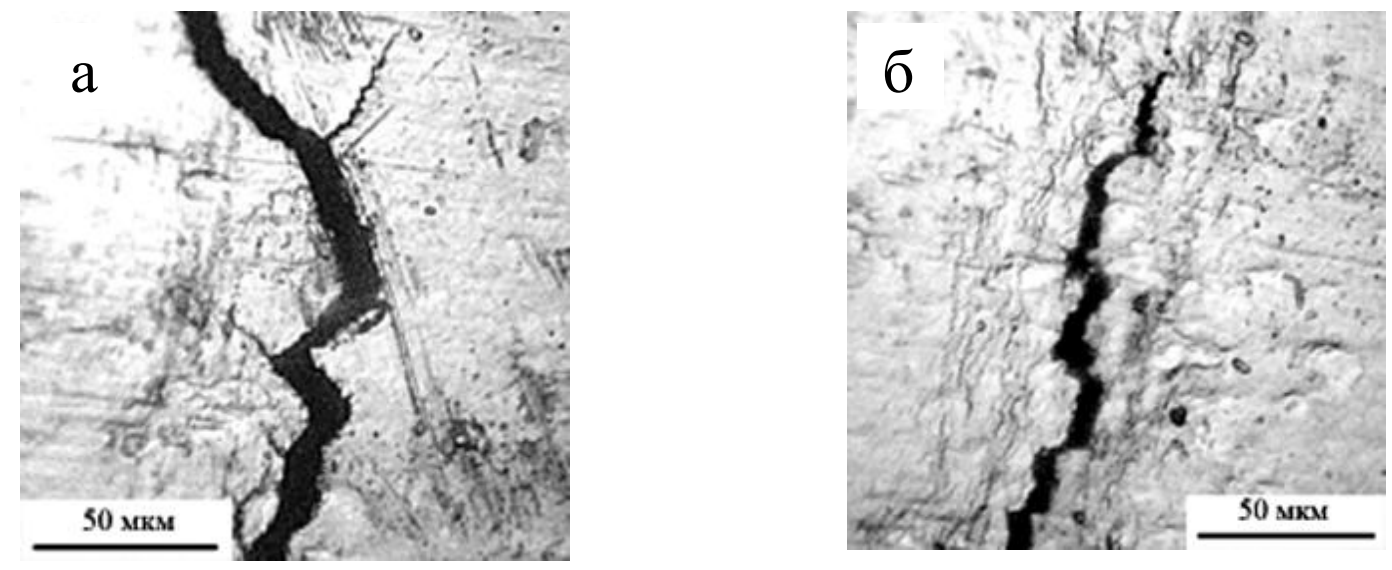

Р и с. 4. Усталостная трещина в СМК Ti Grade-4 со стороны растяжения (а) и сжатия (б). Максимальное напряжение цикла $\sigma_{\max }=560$ МПа. Трещина образовалась после 90000 циклов.

верхности усталостного разрушения расположены нормально по отношению к боковым граням. Излом довольно однороден в центральной части образца и в области, подвергавшейся при циклировании растяжению. Область сжатия имеет несколько отличный вид и отделена от остальной поверхности четкой границей, проходящей вдоль всего образца. По-видимому, это зона долома. Ширина этой зоны составляет 25 - 40 мкм. Характер излома ближе к квазихрупкому. На изломе наблюдается значительное количество вторичных трещин.

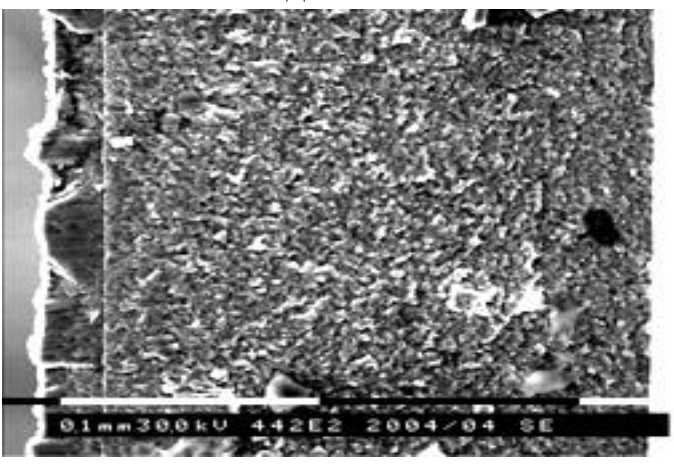

Р и с. 5. Поверхность излома в СМК Ті Grade 4

Электронномикроскопическими исследованиями было установлено, что материалы в состоянии после РКУ прессования имеют зеренно-субзеренную структуру, в которой большеугловые границы составляют около $50 \%$ (рис. $6, a$ ). Плотность дислокаций внутри зерен довольно высока и достигает $\rho=2 \cdot 10^{10} \mathrm{~cm}^{-2}$. Наличие контуров экстинкции и азимутального размытия рефлексов на микродифракционной картине свидетельствует о значительных остаточных дальнодействующих напряжениях [6]. В состоянии после РКУ прессования границы зерен в исследованных материалах являются неравновесными [1], однако на границах некоторых зерен имеется полосчатый контраст, характерный для равновесных границ. По-видимому, при охлаждении от температуры РКУ прессования в материале происходят процессы возврата.

После усталостного разрушения в областях, примыкающих к излому, по всей толщине образца увеличивается плотность дислокаций примерно в 2,5 раза и становится равной $5 \cdot 10^{10} \mathrm{~cm}^{-2}$ (рис. 6, б). Экстинкционные контура становятся более широкими, что говорит о снижении уровня остаточных напряжений. Рефлексы на микродифракционной картине, которые в материале до испытаний имели азимутальное размытие, распадаются на несколько рефлексов, что является следствием образования новых фрагментов. Увеличиваются разориентировки между имевшимися фрагментами, достигая большеугловых. На изображениях наблюдаются элементы, 
которые по морфологическим признакам можно интерпретировать как двойники (на рис.6, б отмечен стрелкой). Однако, поскольку подробного анализа не проводилось, однозначно утверждать это нельзя. В некоторых случаях наблюдали петлеобразные конфигурации фрагментированной структуры, которые можно связать с ротационными модами деформации. Вблизи поверхности разрушения наблюдали также мезополосы локализованной пластической деформации (рис. 7). Эти полосы шириной около 0,5 мкм проходят без изменения направления через большое количество зерен под углом примерно $45^{\circ}$ к поверхности разрушения. Отметим, что области материала, расположенные по обе стороны от полосы локализации, имеют большеугловую разориентировку между собой.
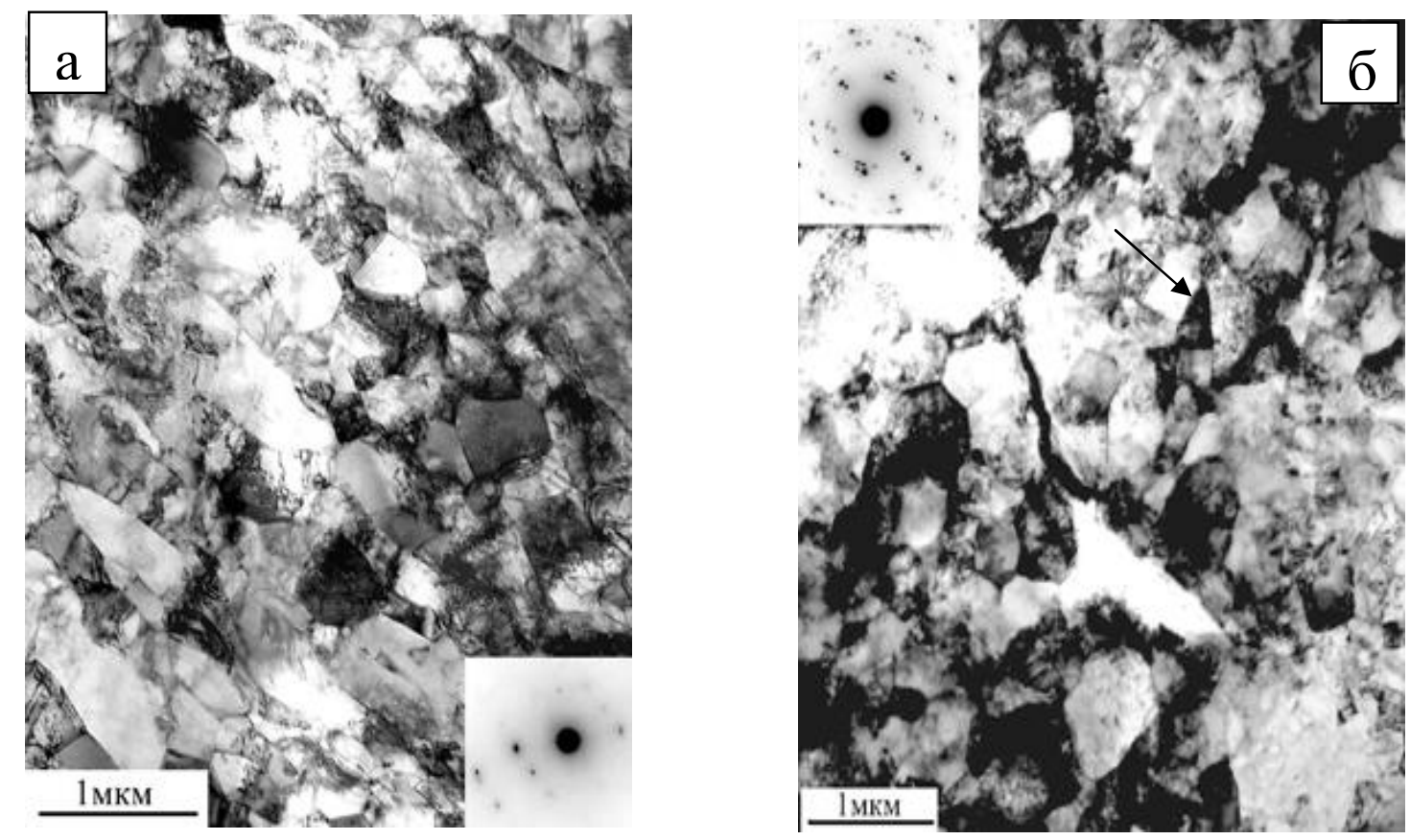

Р и с. 6. Электронномикроскопические изображения с соответствующими картинами микродифракции СМК титана ВТ1-0 до (а) и после циклических испытаний (б)

При удалении от излома вблизи плоской поверхности образца (там, где при циклировании действуют максимальные напряжения) структура является промежуточной между исходной и структурой вблизи излома. Мезополос локализованной пластической деформации не обнаружено. Вдали от излома в центральной части образца микроструктура практически не отличается от исходной. Не обнаружены мезополосы и в неразрушенных образцах после $10^{5}$ циклов.

К настоящему времени пока нет экспериментальных данных о том, отличается ли характер дислокационной структуры после циклических испытаний для титана

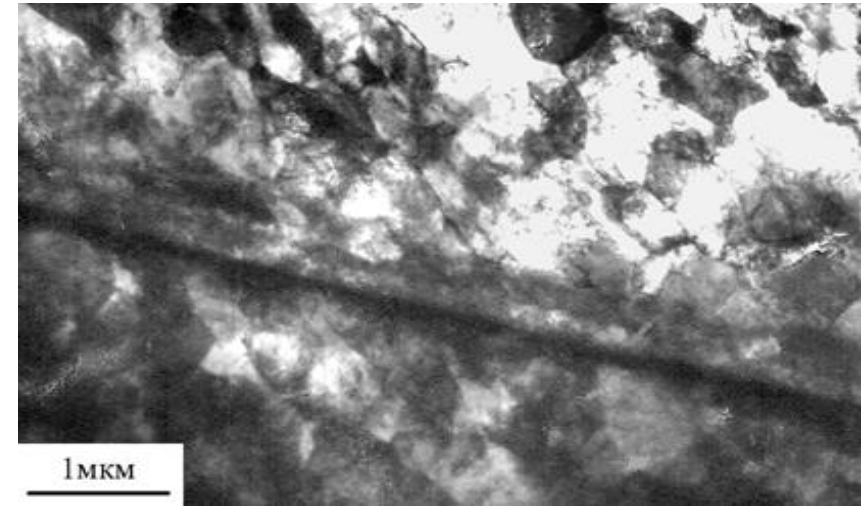

Р и с. 7. Полоса локализованной деформации в СМК титане ВТ1-0 после усталостного разрушения с различным содержанием примесей. Однако, судя по характеру зависимостей накопления остаточной деформации от числа циклов (см. рис. 2), нет оснований ожидать принципиальных различий эволюции микроструктуры для материалов с разной концентрацией примесей.

На основании полученных результатов можно сделать следующее заключение о развитии субструктуры в исследованных материалах при циклическом нагружении. На начальных стадиях циклирования в СМК титане технической чистоты на фоне сформированной в процессе РКУ прессования зеренно-субзеренной структуры идет микропластическая деформация путем зарождения и движения свежих дислокаций. На это указывает увеличение плотности дислокаций, формирование новых фрагментов и увеличение разориентировок между структурными элементами. По-видимому, поскольку РКУ прессование выполняется при температурах $620 \div 670$ К, то 
при последующем охлаждении имеющиеся в материале дислокации становятся заблокированными. Скорость накопления микродеформации даже при высоких максимальных напряжениях цикла сравнительно невысока. Наличие СМК структуры снижает эффективность возникающих в процессе деформации концентраторов напряжений, что обеспечивает их релаксацию за счет дислокаций. Когда в материале на определенном этапе возникают дефекты с линейными размерами, превышающими размер элементов СМК структуры, например, полосы локализации, то релаксация концентраторов напряжений происходит за счет образования трещины. Повидимому, сильная анизотропия свойств в ГПУ структуре титана приводит к тому, что уже первая зародившаяся трещина становится магистральной. Возникающие в голове трещины напряжения определяют более интенсивное развитие пластической деформации и образование вторичных трещин вдоль траектории её распространения. К сожалению, полученные результаты не позволяют однозначно утверждать, что именно мезополосы локализованной деформации являются причиной образования трещины.

Таким образом, получены следующие результаты.

1. Формирование субмикрокристаллического состояния в титане технической чистоты методом равноканального углового прессования приводит к улучшению размерной стабильности материала при квазистатическом и циклическом нагружении. Предел выносливости при этом повышается почти в 1,5 раза по сравнению с крупнозернистым титаном.

2. При знакопостоянном циклическом изгибе формированию магистральной трещины предшествует микропластическая деформация, обусловленная эволюцией дислокационной субструктуры.

3. Вблизи области распространения магистральной усталостной трещины процессы пластической деформации развиваются наиболее интенсивно, однако по имеющимся данным нельзя однозначно сказать, происходит ли локализация деформации до образования магистральной трещины, или же это является процессом, сопутствующим распространению трещины.

\section{БИБЛИОГРАФИЧЕСКИЙ СПИСОК}

1. Валиев Р.З., Александров И.В. Наноструктурные материалы, полученные интенсивной пластической деформацией. М.: Логос, 2000. 272 с.

2. Зернограничная диффузия и свойства наноструктурных материалов. Под ред. Ю.Р. Колобова и Р.3. Валиева. Новосибирск: Наука, 2001. 232 с.

3. Цвиккер У. Титан и его сплавы. М.: Металлургия, 1979. 512 с.

4. Дударев Е.Ф., Кашин О.А., Колобов Ю.Р., Почивалова Г.П., Иванов К.В., Валиев Р.З. Микропластическая деформация поликристаллического и субмикрокристаллического титана при статическом и циклическом нагружении // Изв. вузов. Физика. 1998. №12. С. 20-25.

5. Дударев Е.Ф. Микропластическая деформация и предел текучести поликристаллов. Томск: Изд-во Томского университета, 1988. $256 \mathrm{c}$.

6. Утевский Л.М. Дифракционная электронная микроскопия в металловедении. М.: Металлургия, 1973. 384 с.

Работа выполнена при финансовой поддержке МНТЦ (грант №2398) и ИНТАС (грант №01-320).

УДК 539.3.621.499

\section{М.Н. Коновалов, Г.П. Дроздовский}

\section{РАСЧЕТ РЕАКТИВНЫХ УСИЛИЙ И НАПРЯЖЕНИЙ В СИСТЕМЕ, СОСТОЯЩЕЙ ИЗ ТРУБКИ С ЭПФ И УПРУГОГО КОНТРТЕЛА}

Разработана методика расчета реактивных напряжений и усилий, генерируемых в системе, состоящей из трубки с ЭПФ и упругого контртела, выполненного в виде витой пружсны, функционируюшей при обратимых мартенситных переходах. В основу способа положены классические методы сопротивления материалов в сочетании с представлениями об обратимом характере изменения фазы и деформации при обратимых мартенситных переходах.

Хорошо известно, что материалам с эффектом памяти формы (ЭПФ) можно сообщить способность к многократно обратимому формоизменению путем термоциклирования через интервалы мартенситных переходов в нагруженном состоянии [1-3]. В дальнейшем эффект многократно обратимой (циклической) памяти формы (ЦПФ) может быть реализован как в нагруженном, так и разгруженном состояниях. В данной работе рассмотрен случай, когда внешнее воздействие на рабочее тело из материала с ЭПФ воссоздается за счет линейно-упругого эле- 